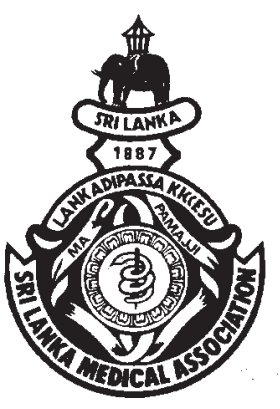

Editors Emeritus

Chris G Uragoda MD, FRCP

Colvin Goonaratna FRCP, PhD

Janaka de Silva DPhil, FRCP

Anuruddha Abeygunasekera MS, FRCS

Editors

Senaka Rajapakse MD, FRCP

A Pathmeswaran MBBS, MD

\section{Section Editors}

B J C Perera MD, FRCPCH

Shalini Sri Ranganathan MD, PhD

\section{Assistant Editors}

Carukshi Arambepola MBBS, MD

Ajith de Silva Nagahawatte MBBS, MD

Ranil Fernando FRCS, PhD

Raveen Hanwella MBBS, MD

Renuka Jayatissa MD, MSc

Sarath Lekamwasam MD, PhD

Udaya K Ranawaka MD, FRCP

Sachith Mettananda MBBS, MD

Shamini Prathapan MBBS, MD

Sisira Siribaddana MD, FRCP

International Advisory Board

SArulkumaran FRCOG, PhD

London, UK

Zulfiqar Ahmed Bhutta FRCPCH, PhD

Karachi, Pakistan

Andrew Dawson FRACP

Sydney, Australia

Barbara Gastel MD, MPH

Texas, USA

Kalle Hoppu MD, PhD

Helsinki, Finland

David Lallo MD, FRCP

Liverpool, UK

Ian Pearce BMBS, FRCS

Manchester, UK

Peush Sahni MS, PhD

New Delhi, India

Anita KM Zaidi MMBS, SM

Karachi, Pakistan

\section{THE CEYLON \\ MEDICAL JOURNAL}

\author{
Established 1887 \\ The Official Publication of the \\ Sri Lanka Medical Association \\ Volume 66, No.1, March 2021 \\ Quarterly ISSN 0009-0875
}

\section{What is death, in the $21^{\text {st }}$ century?}

DOI: http://doi.org/10.4038/cmj.v66i1.9347

Ceylon Medical Journal 2021; 66: 1-4

"Death, in itself, is nothing; but we fear, to be we know not what, ......". - John Dryden, Aureng-Zebe

Death, of all things, should be an unequivocal diagnostic entity, but a simple and straightforward answer to the question 'What is death?' appears elusive. Society requires a clear definition of death - 'to define murder and manslaughter, to allow wills to be read, to allow burial or cremation, and to allow grieving to commence' [1]. It is inconceivable, to put it mildly, that there is no global consensus on such a fundamental concept, and a unifying definition of death is clearly an imperative.

\section{Diagnosing death: the evolution of different criteria}

Death can be diagnosed using three different sets of criteria: somatic, circulatory and neurological. Somatic criteria are the features visible on external inspection of a corpse, such as rigor mortis or decomposition [2]. Historical records and literature reveal many practices used to 'confirm' somatic death, such as holding feathers and mirrors to the nose, or submerging the body in water, to detect evidence of breathing [3]. Somatic criteria were the first criteria used, and are still useful in diagnosing death in a community setting, especially after some delay. Bouchut in 1846 proposed the use of the stethoscope for diagnosing death [3], paving the way for the use of circulatory criteria. They are more relevant when death is determined immediately afterwards, especially in a hospital setting.

With the development of intensive care and the capacity to prolong life in people with brain injury, the need for a 'neurological' definition of death was felt. The concept of brain death was introduced by the French neurologists Mollaret and Goulon in their seminal paper 'coma depassé' (beyond coma) in 1959 [3,4]. The term 'brain death' was first used in 1965 in a report of renal transplantation from a heart-beating donor [3]. A landmark publication in 1968 by an Ad Hoc Committee of the Harvard Medical School introduced the broad framework for determining brain death. It defined 'irreversible coma' as the 'new criterion for death', and diagnosis of death required 'abolition of function at cerebral, brain-stem, and often spinal level' [5]. This was followed by the adoption of 'brain stem' criteria for determination of death by the medical community in the UK [6,7]. In 1981, USA instituted the 'Uniform Determination of Death Act' in which death was defined as 'irreversible cessation of circulatory and respiratory functions OR irreversible cessation of all functions 
of the entire brain, including the brain stem'[3]. The currently accepted criteria consist of 3 essential components: an aetiology capable of causing irreversible brain damage, exclusion of reversible causes, and clinical demonstration of deep coma, absent brainstem reflexes and apnoea $[2,8]$.

\section{Diagnosing death: many controversies}

The circulatory criteria remain the most appropriate for diagnosing death outside an ICU setting, but considerable variation is seen in their application [7]. A minimum observation period of apnoea and asystole is required to confirm death following cardiorespiratory arrest. It is baffling that there is no agreement even on this; the observation period varies from 2 minutes in USA and Australia, 5 minutes in the UK and Canada, to 10 minutes in several European countries [2,7]. Recommendations for a minimum observation period are made with the caveat that no attempts at resuscitation should be made during this period [2], which perhaps is itself an admission that it is clearly inadequate.

Determining death by neurological criteria was endorsed by at least 70 countries by 2015 [9], yet there is continued debate regarding the concept of brain death, the criteria used and their application [2,9-15].

\section{The concept of brain death: Are you dead, if you are brain dead?}

Patients who fulfil criteria for brain death continue to show traditional signs of life, such as warm and moist skin, cardiac rhythm and respiration with ventilator support [1]. If sustained with artificial respiration, they maintain diverse bodily functions such as wound healing, growth and sexual maturation in children, and gestation of healthy foetuses in pregnant women $[1,16]$. Belying the label of 'brain death', they continue to show preservation of varied brain functions: osmoregulation via ADH secretion, thermoregulation, secretion of hypophysiotrophic hormones, and preserved EEG activity and sensory/ brainstem evoked potentials $[1,16,17]$. In a study by Grigg et al, $20 \%$ of patients declared brain dead had persistent EEG activity [18]. These findings are inconsistent with a concept of 'whole brain death'.

\section{The criteria for brain death: Are they the same across the world?}

There is a lack of global consensus on even what constitutes death. Some countries consider brain-stem death as death (13\% of countries in an international survey, e.g., UK, Canada, India), whereas most countries (including USA, Australia, Japan) require demonstration of whole brain death $[2,7,11,13,16]$. However, the current criteria and tests used for diagnosis of brain death relate primarily to brain stem function, and are incapable of excluding 'higher brain' functions.

Surveys in the $21^{\text {st }}$ century have consistently highlighted marked international variation in the criteria, protocols and guidelines used in the determination of brain death. Significant disparities are reported in apnoea testing, observation period before death declaration, number of tests required, number and expertise of physicians required to be present, and the use of ancillary testing $[2,9-15,19]$. In a survey of 80 countries (2002), Wijdicks found that apnoea testing was required in only $59 \%$ of countries, the observation period before confirmation of death varied from 2 to 72 hours, and more than one physician was required for confirmation in half of the guidelines [9]. Nearly 20 years later, Lewis et al (2020) reported similar variation in brain death protocols in 83 countries: assessment of coma not mentioned in $10 \%$ of protocols, apnoea testing not listed as a requirement in 9\%, CT or MRI required before determining brain death in only $27 \%$, and the observation period varying between 1-72 hours. A 100\% consensus was not seen regarding any aspect of brain death determination among the protocols studied [11]. In a survey of 91 countries, only five did not require ancillary testing (UK, Ghana, Malta, Jamaica, Trinidad \& Tobago); ancillary tests were mandatory in 22 countries and optional in others [10]. In Sri Lanka, determination of brain death requires loss of 'all functions of the brain', should be made by two doctors independently on two occasions, and 'should not be considered until at least 6 hours after onset of coma' [20, 21]; ancillary tests are not mandatory.

\section{Application of the accepted criteria: more variation}

Even with the criteria for determining brain death well established, application of these criteria can vary considerably. In a study of brain death determination in organ donors in USA, apnoea testing was completed in only $73 \%$ and was not even attempted in $21 \%$; $7 \%$ of decedents without apnoea testing were declared brain dead without confirmatory testing. Only $45 \%$ of death determinations complied with the existing guidelines [14]. In an international survey, 53\% of respondents deviated from the established criteria [10]. Failure to adhere to established criteria may reflect a lack of training. In a study of physicians and nurses involved in organ transplantation, a group expected to have better-than-average knowledge on brain death, two-thirds were unable to correctly identify the legal and medical criteria [22].

\section{Brain death: for organ transplantation?}

From the time of its introduction, the concept of brain death has attracted criticism of being a move to facilitate organ retrieval for transplantation. Wijdicks, who documented the workings of the Harvard Committee that pioneered the concept of brain death, acknowledged the 
'perpetuating concern that the transplant physicians on this committee played a decisive role in the definition of brain death'. He commented, 'I am uncertain ... whether an alleged agenda of facilitating transplantation through a new construct of death existed'. He narrated that the Harvard Committee chair commented: 'Can society afford to lose organs that are now being buried?' [23]. In an international survey, the existence of a transplantation network was found to be more important than the percapita income level of a country in determining the presence of a brain death protocol [10].

There are well documented reports of organs being removed from patients with intact spontaneous respiration yet declared brain dead [24], which are unlikely to enhance public confidence in the process of organ transplantation. Community surveys have consistently highlighted public anxiety of not being dead at the time of organ collection [24], and interestingly, people were more likely to donate the organs of relatives (82\%) than their own (43\%) [24]. It is indeed debatable if society would accept a patient with a beating heart as 'suitably dead' for burial or cremation, if he/she was not a candidate for organ donation.

\section{What is death - in the $21^{\text {st }}$ century?}

The lack of a global consensus has resulted in tremendous variation in the way brain death is determined. We currently have a situation where one may be pronounced dead in one country but considered alive in another. This would be indeed comical, if not for the profound medical, legal and ethical implications of the transition from life to death. A recent court case involving the death of a 13-year-old child following ENT surgery in USA brought into sharp focus the persisting dilemmas regarding determination of brain death $[25,26]$. Notably, the child was kept alive for more than five years after the initial brain death declaration [26]. Are we ready, in the $21^{\text {st }}$ century, to rely on a diagnostic method with less than $100 \%$ sensitivity and specificity, and to accept a 'false positive' diagnosis, in such a fundamental event as death?

There is a clear need for a uniform global framework for determining brain death that is accepted by the medical community as well as the public. In a salutary move, the World Brain Death Project was convened by several international professional organisations to address the persistent controversies regarding brain death. It is indeed surprising that its consensus statement, published in August 2020, is the first international document to address brain death. The statement acknowledges the 'confusion and dilemmas', 'inconsistencies in concept, criteria, practice, and documentation of brain death' and the 'wide variance in practice internationally and within countries' [19]. It recommends abandoning the terms 'whole brain death' and 'brain stem death', and calls for consistency in using the term 'brain death/ death by neurologic criteria' (BD/DNC). It recognises the potential for a false positive diagnosis of death when 'brain stem' criteria are used in primary brainstem or posterior cerebral circulation pathology, and the need for ancillary testing in such situations before brain death is confirmed. It provides clarity on several contentious issues based on consensus, while acknowledging the lack of high-quality data from randomised clinical trials to guide its recommendations. Importantly, it concedes that all countries may not be able to adhere to the recommendations made, and the determination of brain death 'will always be influenced by local factors including religious, societal and cultural perspectives, legal requirements and resource availability’ [19].

\section{The End}

"There's a big difference between mostly dead and all dead. Mostly dead is slightly alive."

- William Goldman, 'The Princess Bride’

'What is death?' and 'What is life?' are questions that mankind has struggled to answer throughout history. Over several centuries, we have witnessed repetitive cycles of controversy: new theological, philosophical or scientific definitions of death, development of criteria based on contemporary technology, and challenges to these definitions and criteria with advances in knowledge. Our feeble attempts at defining death in medical terms suggest that we are no closer to an answer even in the $21^{\text {st }}$ century. Determination of brain death, withdrawal of life support and organ transplantation are intricately intertwined. It is time to disentangle and critically re-evaluate these fundamental issues separately, and perhaps establish legal mechanisms for withdrawal of life support and organ retrieval from patients with irreversible neurological damage who are conceptually 'alive' but unlikely to survive.

Is a state of 'as good as dead' good enough to be labelled as 'dead'? It seems we are still a long way from settling this age-old controversy.

\section{Conflicts of interest}

There are no conflicts of interest.

\section{References}

1. Kerridge IH, Saul P, Lowe M, McPhee J, Williams D. Death, dying and donation: organ transplantation and the diagnosis of death. J Med Ethics 2002; 28: 89-94.

2. Gardiner D, Shemie S, Manara A, Opdam H. International perspective on the diagnosis of death. Br J Anaesth 2012; 108 Suppl 1: i14-i28.

3. Powner DJ, Ackerman BM, Grenvik A. Medical diagnosis of death in adults: historical contributions to current controversies. Lancet 1996; 348: 1219-23. 
4. Laureys S. Death, unconsciousness and the brain. Nat Rev Neurosci 2005; 6: 899-909.

5. A definition of irreversible coma. Report of the Ad Hoc Committee of the Harvard Medical School to Examine the Definition of Brain Death. J Am Med Assoc 1968; 205: 337-40.

6. Diagnosis of brain death. Statement issued by the honorary secretary of the Conference of Medical Royal Colleges and their Faculties in the United Kingdom on 11 October 1976. Br Med J 1976; 2: 1187-8.

7. Bernat JL. Controversies in defining and determining death in critical care. Nat Rev Neurol 2013; 9: 164-73.

8. Wijdicks EFM, Varelas PN, Gronseth GS, Greer DM. Evidence-based guideline update: Determining brain death in adults. Report of the Quality Standards Subcommittee of the American Academy of Neurology. Neurology 2010; 74: 1911-18.

9. Wijdicks EF. Brain death worldwide: accepted fact but no global consensus in diagnostic criteria. Neurology 2002; 58: 20-5.

10. Wahlster S, Wijdicks EF, Patel PV, Greer DM, Hemphill JC, Carone M, et al. Brain death declaration: practices and perceptions worldwide. Neurology 2015; 84: 1870-79.

11. Lewis A, Bakkar A, Kreiger-Benson E, et al. Determination of death by neurologic criteria around the world. Neurology 2020; 95: e299-e309; DOI: 10.1212/WNL. 0000000000009888

12. Greer DM, Varelas PN, Haque S, Wijdicks EF. Variability of brain death determination guidelines in leading US neurologic institutions. Neurology 2008; 70: 284-9.

13. Greer DM, Wang HH, Robinson JD, Varelas PN, Henderson GV, Wijdicks EFM. Variability of Brain Death Policies in the United States. JAMA Neurol 2016; 73: 213-8.

14. Shappell CN, Frank JI, Husari K, Sanchez M, Goldenberg F, Ardelt A. Practice variability in brain death determination: a call to action. Neurology 2013; 81: 2009-14.

15. Lewis A, Liebman J, Bakkar A, et al. Determination of
Brain Death/Death by Neurologic Criteria in Countries in Asia and the Pacific. J Clin Neurol 2020; 16: 480-90.

16. Nair-Collins M. Clinical and ethical perspectives on brain death. Medicolegal and Bioethics 2015; 5: 69-80.

17. Doig, CJ, Burgess, E. Brain death: resolving inconsistencies in the ethical declaration of death. Can J Anaesth 2003; 50: 725-31.

18. Grigg MM, Kelly MA, Celesia GG, Ghobrial MW, Ross ER. Electroencephalographic activity after brain death. Arch Neurol 1987; 44: 948-54.

19. Greer DM, Shemie SD, Lewis A, Torrance S, Varelas P, Goldenberg FD, et al. Determination of Brain Death/Death by Neurologic Criteria: The World Brain Death Project. JAMA 2020; 324: 1078-97.

20. Consolidated Acts. Transplantation of Human Tissues Act (No. 48 of 1987) of Sri Lanka. http://www.commonlii.org/ lk/legis/num_act/tohta48o1987422/index.html

21. Ministry of Health, Sri Lanka. General Circular No 01-37/ 2010. http://www.health.gov.lk/CMS/cmsmoh1/viewcircular. php?cno=01-37/2010\&med=english

22. Youngner SJ, Landefeld CS, Coulton CJ, Juknialis BW, Leary M. 'Brain death' and organ retrieval. A cross-sectional survey of knowledge and concepts among health professionals. JAMA 1989; 261: 2205-10.

23. Wijdicks EF. The neurologist and Harvard criteria for brain death. Neurology 2003; 61: 970-6.

24. Van Norman GA. A matter of life and death. What every anesthesiologist should know about the medical, legal, and ethical aspects of declaring brain death. Anesthesiology 1999; 91: 275-87.

25. Bernat JL, Larriviere D. Areas of persisting controversy in brain death. Neurology 2014; 83: 1394-95.

26. Grisolia JS. The World Brain Death Project: Answering the Wrong Questions. Medpage Today. August 30, 2020. https:/ /www.medpagetoday.com/publichealthpolicy/healthpolicy/ 88327. Accessed 23 September 2020

Udaya K Ranawaka, Faculty of Medicine, University of Kelaniya, Sri Lanka.

Correspondence: UKR, email: <udayaran@kln.ac.lk>. Received 12 January 2021 and revised 22 February 2021 accepted 05 March 2021. 